\title{
Jenis dan Fungsi Tanaman di Jalur Hijau Jalan Affandi, Jalan Laksda Adisucipto, Jalan Babarsari, Jalan Perumnas Seturan, dan Jalan Ring Road Utara (ALABSeRi), Yogyakarta
}

\author{
Plant Types and Function of Street Greenery at Affandi Street, Laksda \\ Adisucipto Street, Babarsari Street, Perumnas Seturan Street, and Ring \\ Road Utara Street (ALABSeRi), Yogyakarta
}

\author{
Ahmad Irfan Syahindra', Sri Trisnowati², dan Siti Nurul Rofiqo Irwan²
}

\begin{abstract}
This study aims to identify the vegetation along Affandi Street, Laksda Adisucipto Street, Babarsari Street, Perumnas Seturan Street, And Ring Road Utara Street (ALABSeRi), to examine the aesthetics and function of shady of trees greenery along $A L A B S e R i$ and to make appropriate to recommend arrangement of greening to make comfort aesthetic. The data collection and analysis were conducted along ALABSeRi on July - December 2012, using the trnsect line method, then proceed with the survey method. From the identification, it had beed obtained 32 types of plants consisiting of 16 species of trees, 4 types of shrub, and 12 types of bush. Based on the questionnaires, the sense of the beauty of the environment along ALABSeRi has an average value of 3 (normal), the sense of comfortable has an average value of 2 (uncomfortable), the sense of cool and hot (thermal) has an average value of 2 (hot), and the shaded area along ALABSeRi has an average value of 3 (unshaded area), so it is required trees arrangement and selection of trees in order to increase their beauty and improve comfortness in the street greenery.
\end{abstract}

Keyword: ALABSeRi, identification, aesthetic function and shady

\section{INTISARI}

Penelitian ini bertujuan mengidentifikasi vegetasi di sepanjang Jalan Affandi, Jalan Laksda Adisucipto, Jalan Babarsari, Jalan Perumnas Seturan, dan Jalan Ring Road Utara (ALABSeRi), mengkaji fungsi estetika dan peneduh penghijau jalan di sepanjang ALABSeRi, dan membuat rekomendasi penataan penghijauan jalan yang nyaman dan estetis. Penelitian ini mulai dari persiapan, pengambilan data sampai olah data dilaksanakan di sepanjang ALABSeRi pada bulan Juli - Desember 2012, dengan menggunakan metode transect line, kemudian dilanjutkan dengan metode survei. Dari identifikasi yang dilakukan, didapatkan 32 jenis tanaman yang terdiri atas 16 jenis pohon, 4 jenis perdu, dan 12 jenis semak. Berdasarkan kuisioner yang disebarkan, rasa keindahan lingkungan di sepanjang ALABSeRi memiliki rata-rata nilai 3 (biasa saja), rasa kenyamanan memiliki rata-rata nilai 2 (tidak nyaman), rasa sejuk dan panas memiliki rata-rata nilai 2 (panas), dan keteduhan lingkungan di sepanjang ALABSeRi memiliki rata-rata nilai 3 (tidak teduh). Oleh karena itu di Jalur Hijau ALABSeRi membutuhkan penataan dan pemilihan jenis tanaman supaya keindahan dan kenyamanannya meningkat.

Kata kunci: ALABSeRi, identifikasi, fungsi estetika dan peneduh

\footnotetext{
1Alumni Fakultas Pertanian Universitas Gadjah Mada, Yogyakarta
}

${ }^{2}$ Fakultas Pertanian Universitas Gadjah Mada, Yogyakarta 


\section{PENDAHULUAN}

Daerah Istimewa Yogyakarta merupakan salah satu provinsi yang mengalami perkembangan secara cepat. Hal ini menyebabkan perlunya dilakukan peningkatan kualitas dan kuantitas ruang terbuka hijau. Salah satu bentuk ruang terbuka hijau yang diperlukan adalah koridor jalan yang berupa jalur hijau.

Jalur hijau jalan adalah area memanjang yang ditanami pepohonan, rerumputan, dan tanaman, jalur hijau ini terdapat di pinggir jalur pergerakan dan/atau median jalan. Ruang terbuka hijau dapat berupa jalur pengaman jalan untuk pejalan kaki, taman pulau yang biasanya terletak di tengah persimpangan jalan, dan taman sudut jalan yang berada di sisi persimpangan jalan. Median jalan adalah ruang di bagian tengah jalan yang berfungsi untuk membagi jalan. Beberapa fungsi jalur hijau jalan yaitu sebagai penyegar udara, peredam kebisingan, mengurangi pencemaran polusi kendaraan, perlindungan bagi pejalan kaki dari hujan dan sengatan matahari, pembentuk citra kota, dan mengurangi peningkatan suhu udara. Selain itu, akar pepohonan dapat menyerap air hujan sebagai cadangan air tanah dan dapat menetralkan limbah yang dihasilkan dari aktivitas perkotaan (Anonimª ${ }^{\mathrm{a}}$ 2011).

Gandawidjaja (1981) mengatakan bahwa penerapan tekhnik lanskap sangat tergantung pada ketepatan pemilihan jenis tanaman. Ketepatan dalam memilih jenis tanaman hias tepi jalan diperlukan untuk mendapatkan kesan visual yang memiliki nilai estetika tinggi, kenyamanan, keamanan, dan manfaat bagi pengguna jalan serta pemeliharaan yang mudah.

Pohon sedang dengan ketinggian 6-15 $\mathrm{m}$ atau pohon tinggi dengan ketinggian di atas $15 \mathrm{~m}$ mempunyai fungsi sebagai tanaman peneduh. Sedangkan pohon dengan ketinggian kurang dari $6 \mathrm{~m}$ dapat dimanfaatkan sebagai peneduh pada taman yang tidak terlalu luas, apabila tanaman tersebut memiliki tajuk yang cukup lebar. Umumnya tajuk tanaman yang memiliki fungsi peneduh memiliki lebar kurang lebih 10 m, seperti Angsana dan Kiara Payung (Lestari dan Kencana, 2008).

Direktorat Jendral Bina Marga Departemen Pekerjaan Umum (1996) mengkategorikan fungsi tanaman tepi jalan menurut penempatan tanaman menjadi tanaman tepi, median jalan, dan tikungan atau persimpangan. Tanaman yang berada di tepi jalan memiliki fungsi sebagai peneduh, penyerap polusi, 
penyerap kebisingan, pemecah angin, dan pembatas pandang. Tanaman yang berada di median jalan berfungsi sebagai penahan silau lampu kendaraan sedangkan tanaman yang berada di tikungan atau persimpangan berfungsi sebagai pengarah dan pembentuk pandang.

Tanaman yang berada di tepi jalan dan median jalan harus memiliki fungsi sebagai control visual. Dalam hal ini, Hakim dan Utomo (2003) menyarankan memilih pohon atau perdu yang padat. Pada jalur jalan raya bebas hambatan, penanaman pohon tidak dibenarkan pada median jalan. Sebaiknya pada median jalan ditanami semak, agar sinar lampu kendaraan dari arah berlawanan dapat dikurangi.

Jalan Affandi, jalan Laksda Adisucipto, jalan Babarsari, jalan Perumnas Seturan, dan jalan Ring Road Utara dipilih sebagai tempat penelitian karena selain terdapat berbagai Perguruan Tinggi, daerah sepanjang jalan ini juga terdapat berbagai perumahan dan pusat perbelanjaan. Penelitian ini dilakukan untuk melihat tingkat kesesuaian fungsi estetika dan peneduh tanaman lanskap yang berada di sepanjang Jalan Affandi, Jalan Laksda Adisucipto, Jalan Babarsari, Jalan Perumnas Seturan, dan Jalan Ring Road Utara. Penelitian ini diperlukan untuk mempertahankan bahkan meningkatkan fungsi tanaman lanskap, menambah keindahan serta menciptakan kenyamanan untuk masyarakat. Fungsi estetika dan peneduh merupakan salah satu fungsi terpenting diantara fungsi-fungsi lain suatu lanskap.

\section{BAHAN DAN METODE}

Bahan yang digunakan pada penelitian ini adalah peta lokasi pengamatan, yaitu Jalan Affandi, Jalan Laksda Adisucipto, Jalan Babarsari, Jalan Perumnas Seturan, Jalan Ring Road Utara, pertanyaan kuesioner, dan tanaman hias, sedangkan alat yang digunakan yaitu: kamera digital, komputer, kuesioner dan alat tulis.

Penelitian ini dilaksanakan dengan membagi lokasi penelitian menjadi 22 titik pengamatan dengan jarak $500 \mathrm{~m}$ pada tiap titik pengamatan pada jalan ALABSeRi. Lokasi pengamatan dapat dilihat pada Gambar 1. Pada setiap titik pengamatan diamati jenis vegetasi dan dilakukan survey keindahan dan kenyamanan. Metode yang digunakan dalam penelitian ini adalah metode survei. 
Penelitian ini dibagi menjadi 4 bagian, yaitu: pengamatan lapangan, pengambilan data, analisis data, dan rumusan rekomendasi pengembangan.

Pengamatan lapangan dilakukan untuk mengetahui keadaan aktual tempat dan mendapatkan data berupa peta dan keadaan wilayah. Metode yang digunakan adalah metode transect line, yaitu metode penelitian dengan menggunakan jarak tertentu sebagai contoh/sampel pengambilan data (Gambar 1). Penelitian ini dilaksanakan di sepanjang ALABSeRi. Penentuan lokasi pengamatan yaitu dengan membagi luas jarak tempuh dari titik awal pengukuran jarak hingga kembali ke tempat semula dibagi dengan $500 \mathrm{~m}$ sehingga didapat 22 titik pengamatan pada alur median jalan. Alasan pengambilan jarak antar titik sebesar $500 \mathrm{~m}$ adalah karena jarak ini sudah dapat mewakili keadaan lingkungan di setiap jalan yang diteliti. Titik awal mulai pengamatan dinamakan titik 1 , sehingga titik terakhir adalah titik 22.

Pada tahap pengumpulan data, data sekunder menjadi acuan pengambilan data primer3 di lapangan. Data tersebut didapatkan dari peta lokasi dan peta dasar atau denah wilayah Jogja serta kondisi geografi wilayah Jogja. Data primer dari pengamatan dan survei yang didapat berupa identifikasi karakteristik tanaman dari segi fisik dan hortikultura. Penilaian kualitas visual diukur melalui kuisioner keindahan dan kenyamanan jalan yang ada di lokasi pengamatan. Kiusioner dilakukan dengan memberikan pertanyaan kepada tiga orang responden di setiap titik-titik pengamatan.

Analisis yang dilakukan berupa identifikasi tanaman serta pemetaan dalam peta dasar. Data yang diperoleh dari survey, direkapitulasi untuk kemudian dianalisis. Survey yang dilakukan terdiri dari fungsi keindahan dan fungsi kenyamanan digunakan sebagai analisis ruang dimana ruang yang terbentuk dari tanaman lanskap di analisis serta dianalisis potensi dan masalah yang ada dari tanaman lanskap yang digunakan untuk penghijauan jalan.

Survey nilai fungsi keindahan dibagi menjadi tiga pertanyaan, yaitu tingkat keindahan yang dirasakan, jenis tanaman yang dirasakan indah, dan nama tanaman yang indah. Survey nilai fungsi keindahan ini kemudian dihitung nilai fungsi tingkat keindahan yang dirasakan, nilai presentase jenis tanaman yang dirasakan indah, dan nilai presentase nama tanaman yang indah. 


\section{Lokasi Penelitian}

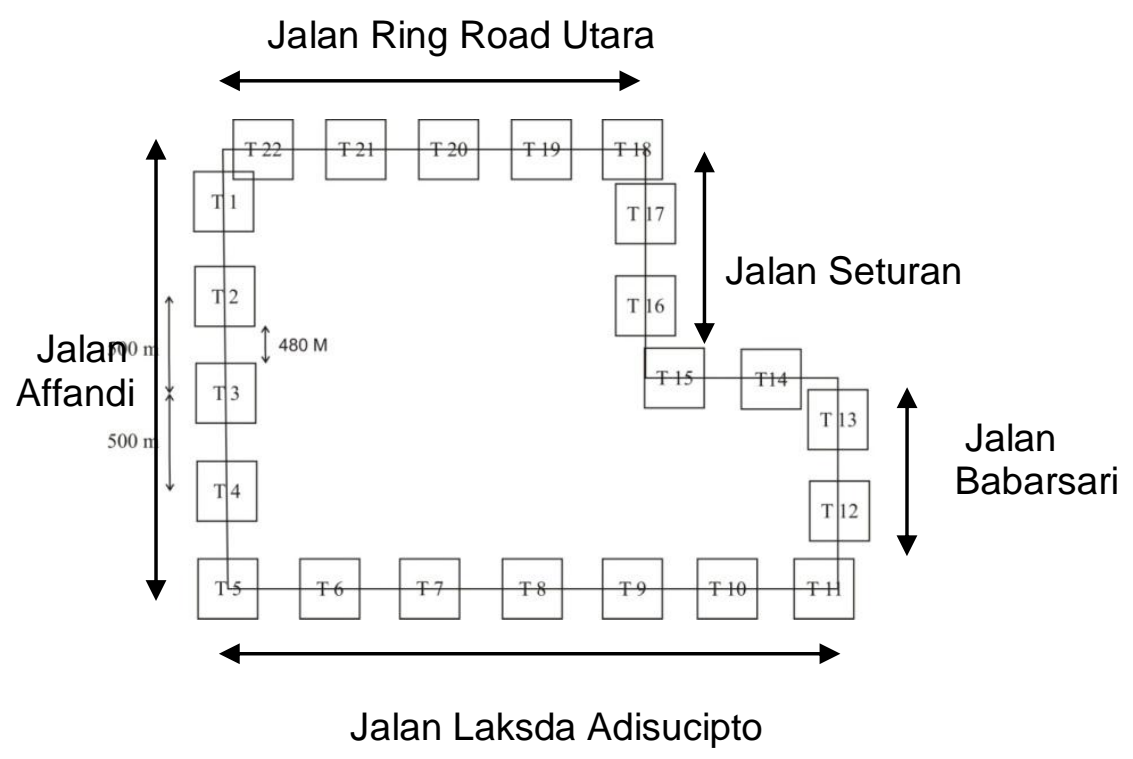

Skema satu titik pengamatan di Jalan Affandi

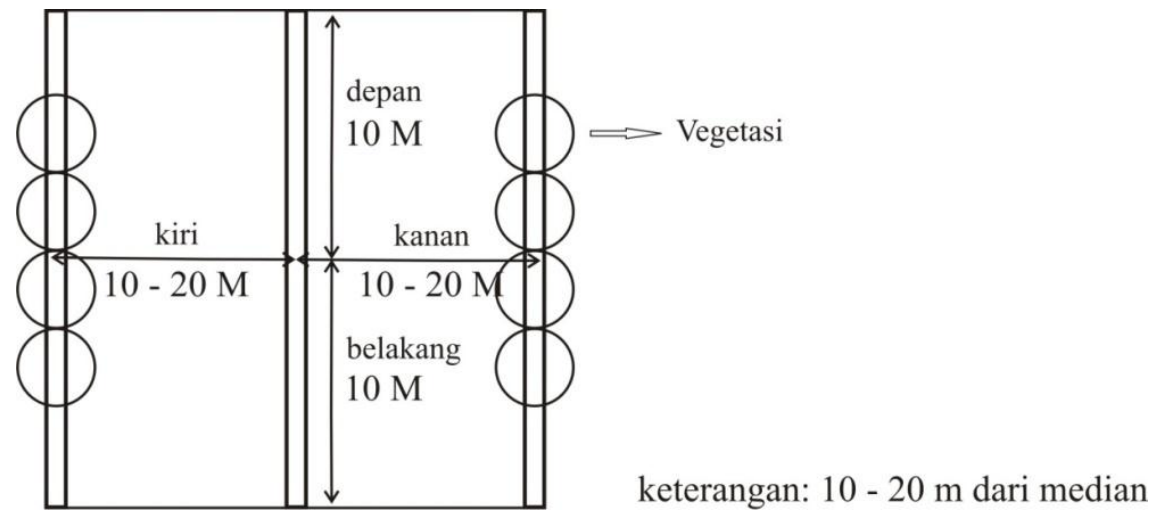

\section{Gambar 1. Skema Pengambilan Sampel Pengamatan}

Survey nilai fungsi kenyamanan dibagi menjadi tiga pertanyaan, yaitu tingkat rasa kenyamanan, tingkat kesejukan atau kepanasan, dan tingkat keteduhan. Survey nilai fungsi keindahan ini kemudian dihitung nilai fungsi tingkat rasa kenyamanan, nilai fungsi tingkat rasa sejuk dan panas, dan nilai fungsi tingkat keteduhan.

Nilai fungsi tingkat keindahan, nilai presentase jenis tanaman yang dirasakan indah, nilai presentase nama tanaman yang indah, nilai fungsi tingkat rasa kenyamanan, nilai fungsi tingkat rasa sejuk dan panas, dan nilai fungsi tingkat keteduhan dihitung berdasarkan data kuisioner hasil survey responden. 


\section{HASIL DAN PEMBAHASAN}

Pengamatan jenis tanaman yang dilakukan di 22 titik pengamatan lokasi penelitian menghasilkan data jumlah vegetasi sebanyak 16 jenis pohon, 4 jenis perdu, dan 12 jenis tanaman semak. Pengamatan dilakukan dengan melihat lokasi tumbuh setiap tanaman di jalan yang menjadi lokasi penelitian.

Pada hasil kuisioner (tabel 1) menunjukkan bahwa hampir semua masyarakat menilai bahwa jenis tanaman yang indah di Jalan ALABSeRi adalah jenis tanaman pohon. Hal ini didukung oleh keadaan bahwa di semua Jalan ALABSeRi lebih banyak tanaman pohon dibandingkan tanaman perdu atau semak. Selain itu hal yang mempengaruhi penilaian masyarakat adalah karena di beberapa titik pengamatan hanya terdapat satu jenis tanaman saja.

Tabel 1 A. Presentase Penilaian Rasa Keindahan Jenis Tanaman

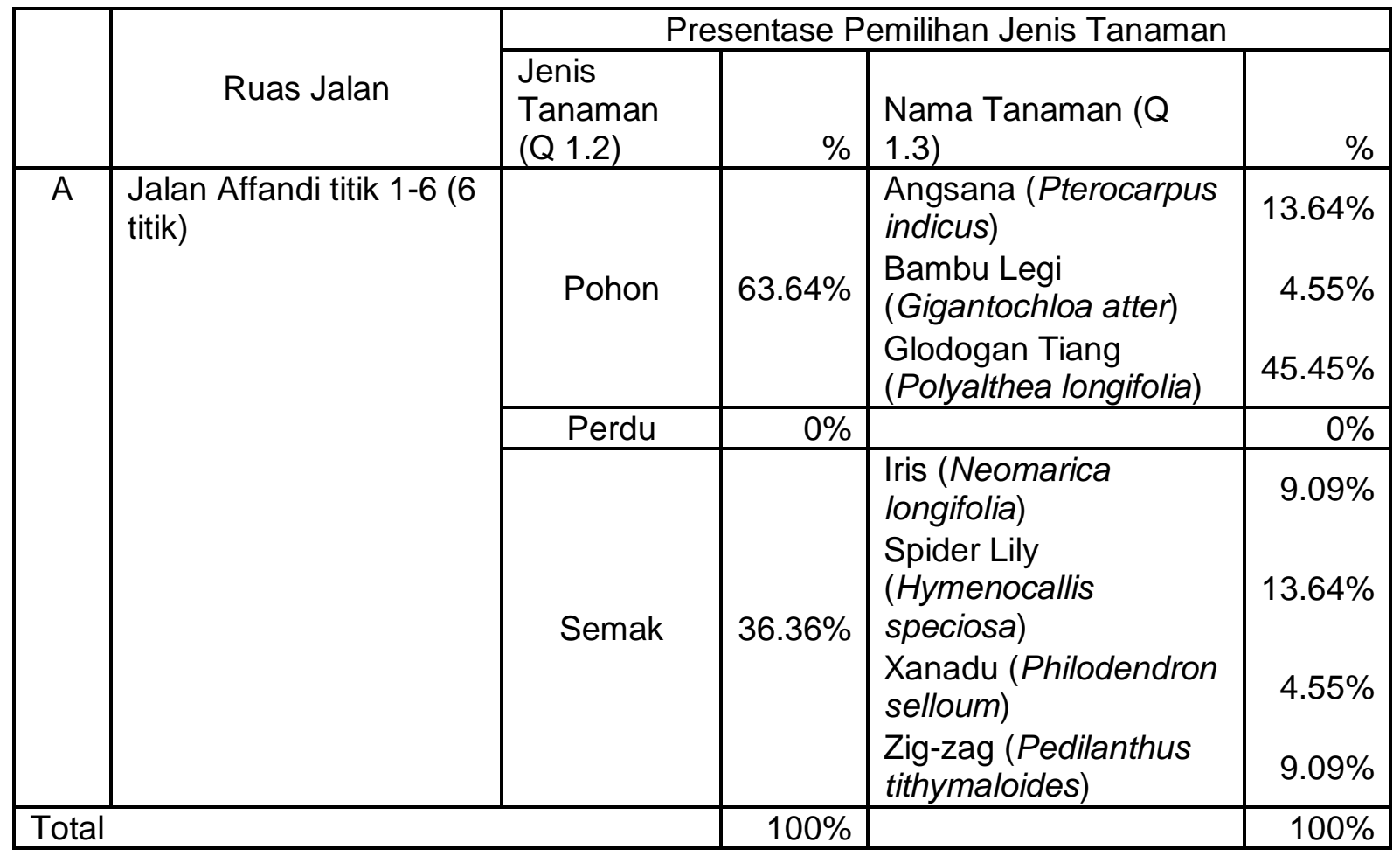

Keindahan tanaman yang paling banyak dipilih oleh masyarakat di Jalan Affandi adalah jenis tanaman pohon, sedangkan tanaman yang dirasa indah adalah Glodogan Tiang (Polyalthea longifolia). Penilaian ini didasari oleh banyaknya tanaman pohon yang ada di Jalan Affandi. Tanaman Glodogan Tiang dipilih oleh masyarakat sebagai tanaman yang indah karena Glodogan Tiang ada hampir disemua titik pengamatan kecuali titik pengamatan 6 dan jumlahnya paling banyak di setiap titik pengamatan di Jalan Affandi. 
Keindahan tanaman yang paling banyak dipilih oleh masyarakat di Jalan Laksda Adisucipto adalah jenis tanaman pohon, sedangkan tanaman yang dinilai indah adalah Glodogan Bulat (Polyalthia Fragrans). Pada Jalan Laksda Adisucipto memiliki banyak tanaman pohon sehingga mendasari pemilihan pohon sebagai jenis tanaman yang indah. Tanaman Glodogan Bulat dipilih oleh masyarakat sebagai tanaman yang indah karena Glodogan Bulat merupakan tanaman utama di median Jalan Laksda Adisucipto dan di beberapa titik pengamatan hanya terdapat Glodogan Bulat yang ditanam.

Tanaman yang paling indah yang banyak dipilih oleh masyarakat di Jalan Babarsari dan Jalan Perumnas Seturan adalah jenis tanaman pohon dan tanaman semak. Jalan Babarsari dan Jalan Perumnas Seturan memiliki banyak tanaman pohon dan semak sehingga mendasari pemilihan pohon dan semak sebagai jenis tanaman yang indah. Pada Jalan Babarsari dan Jalan Perumnas Seturan tanaman Mahoni (Swietenia macrophylla) menjadi tanaman yang paling indah yang dipilih oleh masyarakat. Tanaman Mahoni dapat ditemukan di tiga titik pengamatan dengan jumlah kemunculan yang cukup tinggi.

Tanaman yang paling indah yang banyak dipilih oleh masyarakat di Jalan Ring Road Utara adalah jenis tanaman pohon. Pada Jalan Ring Road Utara memiliki banyak tanaman pohon sehingga mendasari pemilihan pohon sebagai jenis tanaman yang indah. Tanaman Glodogan Bulat (Polyalthia Fragrans) dipilih oleh masyarakat sebagai tanaman yang indah karena Glodogan Bulat merupakan tanaman utama di median Jalan Laksda Adisucipto dan di beberapa titik pengamatan hanya terdapat Glodogan Bulat yang ditanam.

Berdasarkan tabel 2 dapat dilihat bahwa secara keseluruhan tingkat rasa keindahan Jalan Affandi memiliki nilai 2,89, sedangkan tingkat rasa kenyamanan Jalan Affandi memiliki nilai 2,67. Tingkat keteduhan jalan Affandi secara keseluruhan memiliki nilai 2,50. Hal ini menunjukkan bahwa Jalan Affandi dinilai biasa dan tidak begitu nyaman serta berada diantara setengah teduh dan terbuka oleh masyarakat. Nilai rasa keindahan, kenyamanan, sejuk dan panas, dan keteduhan di Jalan Affandi diambil dari nilai rata-rata rasa keindahan setiap titik pengamatan yang berjumlah 6 titik. 
Tabel 1 B,C,D. Presentase Penilaian Rasa Keindahan Jenis Tanaman

\begin{tabular}{|c|c|c|c|c|c|}
\hline \multirow[t]{3}{*}{$B$} & \multirow[t]{3}{*}{$\begin{array}{l}\text { Jalan Laksda } \\
\text { Adisucipto titik 7-12 (6 } \\
\text { titik) }\end{array}$} & Pohon & $63.64 \%$ & $\begin{array}{l}\text { Beringin (Ficus } \\
\text { benjamina) } \\
\text { Glodogan Bulat } \\
\text { (Polyalthia Fragrans) } \\
\text { Ketapang (Terminalia } \\
\text { catappa) } \\
\text { Pucuk Merah } \\
\text { (Syzygium oleina) }\end{array}$ & $\begin{array}{r}9.09 \% \\
40.91 \% \\
4.55 \% \\
9.09 \%\end{array}$ \\
\hline & & Perdu & $18.18 \%$ & $\begin{array}{l}\text { Euphorbia (Euphorbia } \\
\text { milii) } \\
\text { Puring (Codiaeum sp.) }\end{array}$ & $\begin{array}{r}4.55 \% \\
13.64 \%\end{array}$ \\
\hline & & Semak & $18.18 \%$ & $\begin{array}{l}\text { Spider Lily } \\
\text { (Hymenocallis } \\
\text { speciosa) }\end{array}$ & $18.18 \%$ \\
\hline \multicolumn{3}{|c|}{ Total } & $100 \%$ & & $100 \%$ \\
\hline \multirow[t]{3}{*}{$\mathrm{C}$} & \multirow[t]{3}{*}{$\begin{array}{l}\text { Jalan Babarsari dan } \\
\text { Perumnas Seturan } \\
\text { titik 13-18 (6 titik) }\end{array}$} & Pohon & $46.16 \%$ & $\begin{array}{l}\text { Angsana (Pterocarpus } \\
\text { indicus) } \\
\text { Bunga Kupu-kupu } \\
\text { (Bauhinia sp.) } \\
\text { Kiara Payung (Filicium } \\
\text { decipiens) } \\
\text { Mahoni (Swietenia } \\
\text { macrophylla) } \\
\end{array}$ & $\begin{array}{r}3.85 \% \\
11.54 \% \\
3.85 \% \\
26.92 \%\end{array}$ \\
\hline & & Perdu & $7.69 \%$ & Puring (Codiaeum sp.) & $7.69 \%$ \\
\hline & & Semak & $46.16 \%$ & $\begin{array}{l}\text { Keji Beling } \\
\text { (Strobilanthes crispa) } \\
\text { Keladi Hias (Caladium } \\
\text { hortulanum) } \\
\text { Iris (Neomarica } \\
\text { longifolia) } \\
\text { Teh-tehan (Acalypha } \\
\text { siamensis) }\end{array}$ & $\begin{array}{r}23.08 \% \\
3.85 \% \\
15.38 \% \\
3.85 \%\end{array}$ \\
\hline \multicolumn{3}{|c|}{ Total } & $100 \%$ & & $100 \%$ \\
\hline \multirow[t]{3}{*}{$\mathrm{D}$} & \multirow[t]{3}{*}{$\begin{array}{l}\text { Jalan Ring Road Utara } \\
\text { titik 19-22 (4 titik) }\end{array}$} & Pohon & $100 \%$ & $\begin{array}{l}\text { Glodogan Bulat } \\
\text { (Polyalthia Fragrans) } \\
\text { Mahoni (Swietenia } \\
\text { macrophylla) } \\
\text { Mangga (Mangifera } \\
\text { indica) }\end{array}$ & $\begin{array}{l}53.85 \% \\
23.08 \% \\
23.08 \%\end{array}$ \\
\hline & & Perdu & $0 \%$ & & $0 \%$ \\
\hline & & Semak & $0 \%$ & & $0 \%$ \\
\hline \multicolumn{3}{|c|}{ Total } & $100 \%$ & & $100 \%$ \\
\hline
\end{tabular}


Tabel 2. Nilai rasa keindahan dan kenyamanan di titik pengamatan jalan ALABSeRi

\begin{tabular}{|c|c|c|c|c|c|}
\hline & \multirow[b]{2}{*}{ Ruas Jalan } & \multirow{2}{*}{$\begin{array}{l}\begin{array}{l}\text { Fungsi } \\
\text { Keindaha } \\
\mathrm{n}(\mathrm{Q} 1)\end{array} \\
\begin{array}{l}\text { Nilai Rasa } \\
\text { Keindaha } \\
\mathrm{n}(1-5)\end{array} \\
\end{array}$} & \multicolumn{3}{|c|}{ Fungsi Kenyamanan (Q 2) } \\
\hline & & & $\begin{array}{l}\text { Nilai Rasa } \\
\text { Kenyamana } \\
\mathrm{n}(1-5)\end{array}$ & $\begin{array}{l}\text { Nilai Rasa } \\
\text { Sejuk dan } \\
\text { Panas (1- } \\
\text { 5) }\end{array}$ & $\begin{array}{l}\text { Nilai } \\
\text { Keteduha } \\
\text { n (1-3) }\end{array}$ \\
\hline $\bar{A}$ & $\begin{array}{l}\text { Jalan Affandi titik 1-6 } \\
\text { (6 titik) }\end{array}$ & 2,89 & 2,67 & 2,06 & 2,50 \\
\hline$B$ & $\begin{array}{l}\text { Jalan Laksda } \\
\text { Adisucipto titik 7-12 (6 } \\
\text { titik) }\end{array}$ & 2,61 & 2,39 & 2,22 & 2,67 \\
\hline $\mathrm{C}$ & $\begin{array}{l}\text { Jalan Babarsari dan } \\
\text { Perumnas Seturan }\end{array}$ & 2,28 & 2,44 & 2,22 & 2,50 \\
\hline $\mathrm{D}$ & $\begin{array}{l}\text { Jalan Ring Road Utara } \\
\text { titik 19-22 (4 titik) }\end{array}$ & 2,25 & 2,00 & 1,75 & 3,00 \\
\hline & Total & 2,53 & 2,41 & 2,09 & 2,64 \\
\hline
\end{tabular}

Keterangan: skor Nilai Rasa Keindahan: 1 = sangat tidak indah; 2 = tidak indah; 3 = biasa saja; 4 = indah; 5 = sangat indah; skor Nilai Rasa Kenyamanan: 1 = sangat tidak nyaman, 2 = tidak nyaman, $3=$ biasa saja, 4 = nyaman, 5 = sangat nyaman; skor Nilai Rasa Sejuk dan Panas: 1 = sangat panas, $2=$ panas, $3=$ hangat, $4=$ sejuk, 5 = sangat sejuk; skor Nilai Keteduhan: 1 = teduh penuh, $2=$ setengah teduh, $3=$ terbuka

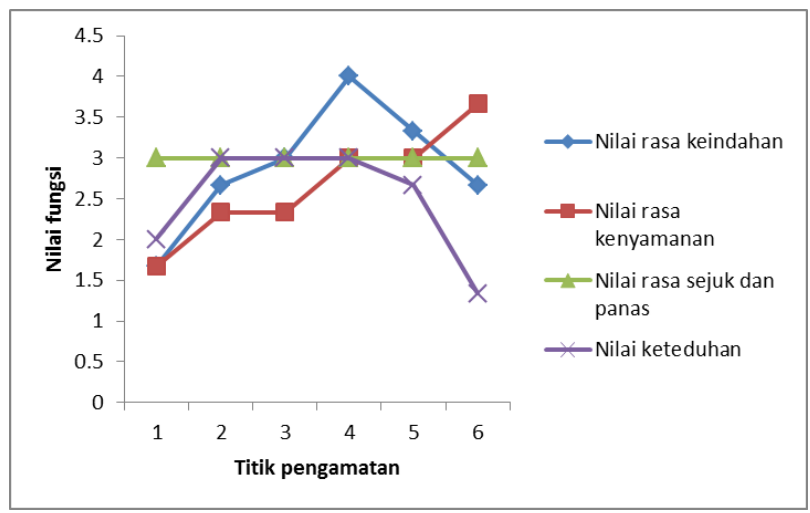

Gambar 2. Rerata nilai rasa keindahan, kenyamanan, sejuk dan panas, dan keteduhan lingkungan di masing-masing titik pengamatan Jalan Affandi

Gambar 2 menunjukkan bahwa rasa keindahan di Jalan Affandi mempunyai nilai tertinggi terdapat pada titik pengamatan 4. Hal ini menunjukkan bahwa perpaduan tanaman yang terdapat di titik pengamatan 4 (Glodogan Tiang dan Spider Lily) mampu memberikan rasa keindahan bagi masyarakat. Nilai rasa kenyamanan di Jalan Affandi pada gambar 8 menunjukkan bahwa titik 
pengamatan 6 dirasakan paling nyaman adalah pada titik pengamatan 6 . Hal ini disebabkan titik pengamatan 6 terdapat pohon Angsana yang memiliki tajuk yang besar ditanam tersusun di pembatas jalan, sehingga meemberikan rasa kenyamanan kepada masyarakat. Nilai rasa sejuk dan panas di Jalan Affandi pada gambar 2 menunjukkan bahwa seluruh titik pengamatan dinilai hangat oleh masyarakat. Hal ini dikarenakan masih sedikitnya jumlah tanaman yang dapat memberikan kehangatan pada masyarakat di Jalan Affandi. Gambar 2 menunjukkan bahwa keteduhan di Jalan Affandi mempunyai nilai tertinggi terdapat pada titik pengamatan 6 . Hal ini menunjukkan bahwa tanaman yang terdapat di titik pengamatan 6 terutama pohon Angsana mampu memberikan rasa keteduhan bagi masyarakat.

Berdasarkan tabel 2 di atas dapat dilihat bahwa secara keseluruhan tingkat rasa keindahan Jalan Laksda Adisucipto memiliki nilai 2,61. Hal ini menunjukkan bahwa Jalan Laksda Adisucipto dinilai biasa saja oleh masyarakat, sehingga perlu dilakukan upaya untuk menambah tingkat rasa keindahan Jalan Laksda Adisucipto. Secara keseluruhan tingkat rasa kenyamanan Jalan Laksda Adisucipto memiliki nilai 2,39. Hal ini menunjukkan bahwa Jalan Laksda Adisucipto dinilai tidak nyaman oleh masyarakat. Nilai rasa keindahan, kenyamanan, sejuk dan panas serta keteduhan Jalan Laksda Adisucipto diambil dari nilai rata-rata rasa kenyamanan setiap titik pengamatan yang berjumlah 6 titik.

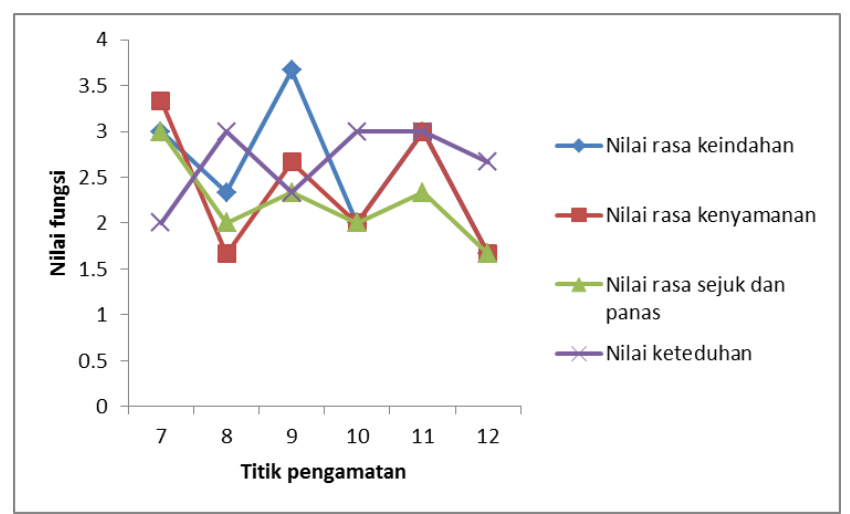

Gambar 3. Rerata nilai rasa keindahan, kenyamanan, sejuk dan panas, dan keteduhan lingkungan di masing-masing titik pengamatan Jalan Laksda Adisucipto

Gambar 3 menunjukkan bahwa rasa keindahan di Jalan Laksda Adisucipto mempunyai nilai tertinggi terdapat pada titik pengamatan 9 . Hal ini 
menunjukkan bahwa walaupun hanya ada satu tanaman di titik ini, yaitu pohon Glodogan Bulat, tetapi mampu memberikan rasa keindahan bagi masyarakat. Nilai rasa kenyamanan di Jalan Laksda Adisucipto pada gambar 15 menunjukkan bahwa titik pengamatan 7 dirasakan paling nyaman. Hal ini disebabkan titik pengamatan 7 mempunyai berbagai jenis tanaman dan memiliki kerapatan tanaman yang tinggi sehingga meemberikan rasa kenyamanan kepada masyarakat. Nilai rasa sejuk dan panas di Jalan Laksda Adisucipto pada gambar 3 menunjukkan bahwa titik pengamatan 7 dinilai paling sejuk oleh masyarakat. Hal ini dikarenakan titik pengamatan 7 mempunyai tanaman yang padat yang dapat memberikan kesejukkan pada masyarakat di Jalan Laksda Adisucipto. Gambar 3 menunjukkan bahwa keteduhan di Jalan Laksda Adisucipto mempunyai nilai tertinggi terdapat pada titik pengamatan 7. Hal ini menunjukkan bahwa tanaman yang terdapat di titik pengamatan 7 terutama di bagian utara jalan mampu memberikan rasa keteduhan bagi masyarakat.

Berdasarkan tabel 2 di atas dapat dilihat bahwa secara keseluruhan tingkat rasa keindahan jalan Babarsari dan jalan Perumnas Seturan memiliki nilai 2,28. Hal ini menunjukkan bahwa jalan Babarsari dan jalan Perumnas Seturan dinilai tidak indah oleh masyarakat, sehingga perlu dilakukan upaya keras untuk menambah tingkat rasa keindahannya. Secara keseluruhan tingkat rasa kenyamanan jalan Babarsari dan jalan Perumnas Seturan memiliki nilai 2,44. Hal ini menunjukkan bahwa Jalan Babarsari dan jalan Perumnas Seturan dinilai tidak nyaman oleh masyarakat. Nilai rasa keindahan, kenyamanan, sejuk dan panas serta keteduhan jalan Babarsari dan jalan Perumnas Seturan diambil dari nilai rata-rata rasa kenyamanan setiap titik pengamatan yang berjumlah 6 titik.

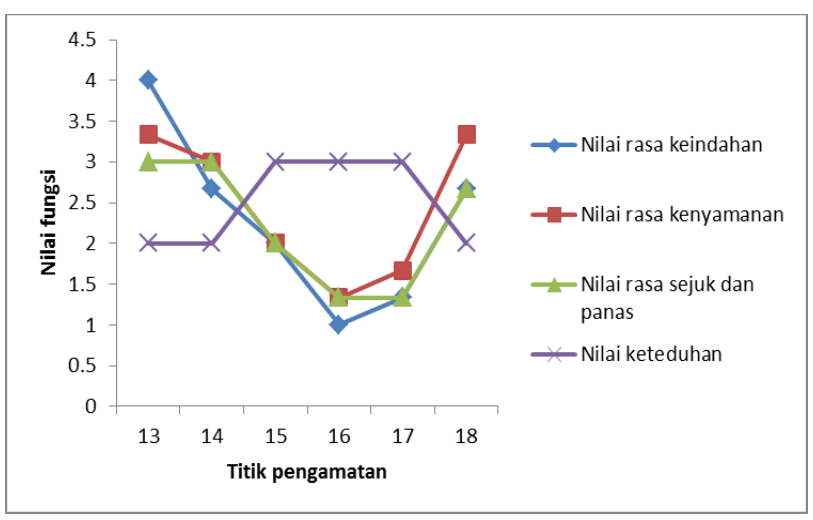

Gambar 4. Rerata nilai rasa keindahan, kenyamanan, sejuk dan panas, dan keteduhan lingkungan di masing-masing titik pengamatan Jalan Babarsari dan Jalan Perumnas Seturan 
Gambar 4 menunjukkan bahwa rasa keindahan di Jalan Babarsari dan Jalan Perumnas Seturan mempunyai nilai tertinggi terdapat pada titik pengamatan 13. Hal ini disebabkan di titik pengamatan 13 terdapat tanaman yang disusun dengan baik sehingga mampu memberikan rasa yang paling indah bagi masyarakat. Nilai rasa kenyamanan di Jalan Babarsari dan Jalan Perumnas Seturan pada gambar 4 menunjukkan bahwa titik pengamatan 13 dan titik pengamatan 18 dirasakan paling nyaman. Hal ini disebabkan titik pengamatan 13 mempunyai tanaman yang indah sehingga dapat memberikan rasa yang paling nyaman kepada masyarakat, sedangkan titik pengamatan 18 mempunyai Pohon Mahoni yang besar sehingga dapat memberikan rasa paling nyaman pada masyarakat. Nilai rasa sejuk dan panas di Jalan Babarsari dan Jalan Perumnas Seturan pada gambar 4 menunjukkan bahwa titik pengamatan 13 dan titik pengamatan 14 mempunyai tanaman yang ditanam secara rapat sehingga dinilai paling sejuk oleh masyarakat. Gambar 4 menunjukkan bahwa keteduhan di Jalan Babarsari dan Jalan Perumnas Seturan mempunyai nilai tertinggi terdapat pada titik pengamatan 13, 14, dan 18. Hal ini menunjukkan bahwa tanaman yang terdapat di titik pengamatan 13, 14, dan 18 mempunyai tanaman yang dapat memberikan rasa keteduhan bagi masyarakat.

Berdasarkan tabel 2 di atas dapat dilihat bahwa secara keseluruhan tingkat rasa keindahan jalan Ringroad Utara memiliki nilai 2,25. Hal ini menunjukkan bahwa jalan Ringroad Utara dinilai tidak indah oleh masyarakat, sehingga perlu dilakukan upaya keras untuk menambah tingkat rasa keindahannya. Secara keseluruhan tingkat rasa kenyamanan jalan Ringroad Utara memiliki nilai 2,00. Hal ini menunjukkan bahwa Jalan Ringroad Utara dinilai tidak nyaman oleh masyarakat. Nilai rasa keindahan, kenyamanan, sejuk dan panas serta keteduhan Jalan Ringroad Utara diambil dari nilai rata-rata rasa kenyamanan setiap titik pengamatan yang berjumlah 4 titik. 


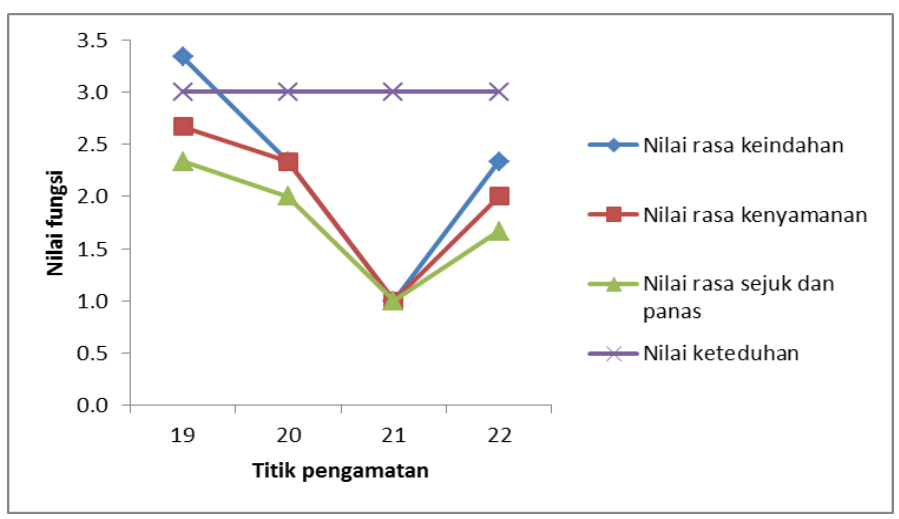

Gambar 5. Rerata nilai rasa keindahan, kenyamanan, sejuk dan panas, dan keteduhan lingkungan di masing-masing titik pengamatan Jalan Ring Road Utara

Gambar 5 menunjukkan bahwa rasa keindahan di Jalan Ring Road Utara mempunyai nilai tertinggi terdapat pada titik pengamatan 19. Hal ini disebabkan di titik pengamatan 19 terdapat tanaman pohon yang disusun di sisi selatan jalan di pinggir pagar universitas sehingga mampu memberikan rasa yang paling indah bagi masyarakat. Nilai rasa kenyamanan di Jalan Ring Road Utara pada gambar 5 menunjukkan bahwa titik pengamatan 19 dirasakan paling nyaman. Hal ini disebabkan titik pengamatan 19 mempunyai tanaman pohon yang disusun cukup rapi sehingga dapat memberikan rasa paling nyaman kepada masyarakat. Nilai rasa sejuk dan panas di Jalan Ring Road Utara pada gambar 5 menunjukkan bahwa titik pengamatan 19 dinilai paling sejuk oleh masyarakat. $\mathrm{Hal}$ ini dikarenakan titik pengamatan 19 mempunyai tanaman pohon yang padat yang ditanam secara rapi sehingga dapat memberikan rasa paling sejuk pada masyarakat di Jalan Ringroad Utara. Gambar 5 menunjukkan bahwa keteduhan di Jalan Ringroad Utara mempunyai nilai setara pada semua titik pengamatan. $\mathrm{Hal}$ ini menunjukkan bahwa tanaman yang terdapat di semua titik pengamatan belum mempunyai tanaman yang cukup untuk dapat memberikan rasa keteduhan bagi masyarakat.

\section{KESIMPULAN}

1. Di penghijauan Jalan Alabseri didominasi jenis pohon, dengan nilai estetika tertinggi pohon Glodogan Tiang (Jalan Affandi), pohon Glodogan Bulat (Jalan Laksda Adisucipto dan Jalan Ring Road Utara), dan pohon Mahoni (Jalan Babarsari dan Jalan Perumnas Seturan). 
2. Jalan Affandi memiliki nilai keindahan tertinggi dibanding jalan yang lain di ALABSeRi, yaitu 2,89 (biasa saja), dan nilai kenyamanan 2,67 (biasa saja). Kondisi Jalan ALABSeRi memiliki nilai 2,22 (panas) dan 2,5 (setengah teduh).

3. Rekomendasi pengembangan kawasan jalur hijau di ALABSeRi, yaitu: pada median jalan dilakukan perawatan tanaman pohon agar tidak menutupi pandangan, untuk keteduhan pada trotoar jalan diberi pergola dengan tanaman merambat seperti Nona Makan Sirih (Clerondendrum thomsoniae), Pasiflora (Passiflora vitifolia), Alamanda (Allamanda cathartica), Thunbergia (Thunbergia erecta), atau tanaman merambat hias lainnya, di beberapa titik pada trotoar direncanakan kembali penanaman pohon perindang di kedua sisi jalan, sehingga dapat tercipta payung alami.pada trotoar dapat ditanami tanaman pohon perindang di kedua sisi jalan, sehingga dapat tercipta payung alami.

\section{UCAPAN TERIMA KASIH}

Ucapan terima kasih disampaikan kepada seluruh pihak yang telah membantu penelitian ini.

\section{DAFTAR PUSTAKA}

Anonim. 2011. Pedoman Penyediaan dan Pemanfaatan Ruang Terbuka Hijau di Kawasan Perkotaan. $<$ http://www.penataanruang.net/taru/upload/nspk/ pedoman/RTH/ 8.Bab3.pdf>. diakses tanggal 21 Agustus 2014.

Gandawidjaja, D. 1981. Lanskap untuk Penghematan Energi. Buletin Kebun Raya 5(3):57-60.

Lestari, G. dan I. P. Kencana. 2008. Galeri Tanaman Hias Lanskap. Penebar Swadaya, Jakarta.

Direktorat Jendral Bina Marga Departemen Pekerjaan Umum. 1996. Tata Cara Perencanaan Teknik Lanskap Jalan. Jakarta.

Hakim, R. Dan H. Utomo. 2003. Komponen Perancangan Arsitektur Lanskap: Prinsip-Unsur dan Aplikasi. Bumi Aksara, Jakarta. 